This item was submitted to Loughborough's Research Repository by the author.

Items in Figshare are protected by copyright, with all rights reserved, unless otherwise indicated.

\title{
Differentiated perceived exertion and self-regulated wheelchair exercise
}

PLEASE CITE THE PUBLISHED VERSION

http://dx.doi.org/10.1016/j.apmr.2013.03.018

\section{PUBLISHER}

Elsevier (@ American Congress of Rehabilitation Medicine)

VERSION

AM (Accepted Manuscript)

\section{PUBLISHER STATEMENT}

This work is made available according to the conditions of the Creative Commons Attribution-NonCommercialNoDerivatives 4.0 International (CC BY-NC-ND 4.0) licence. Full details of this licence are available at: https://creativecommons.org/licenses/by-nc-nd/4.0/

\section{LICENCE}

CC BY-NC-ND 4.0

\section{REPOSITORY RECORD}

Paulson, Thomas A.W., Nicolette Bishop, Roger G. Eston, and Victoria L. Goosey-Tolfrey. 2019.

"Differentiated Perceived Exertion and Self-regulated Wheelchair Exercise". figshare.

https://hdl.handle.net/2134/22648. 


\section{Abstract (272 words max)}

4 Objective: To investigate the utility of the differentiated ratings of perceived exertion (RPE)

5 for the self-regulation of sub-maximal wheelchair propulsion in novice users.

6 Design: Each participant completed a sub-maximal incremental test and a graded test to

7 exhaustion to determine peak oxygen uptake ( $\dot{\mathrm{V}} \mathrm{O}_{2 \text { peak }}$ ) on a wheelchair ergometer. On a

8 separate day, two 12-min intermittent bouts consisting of three 4-min stages were completed

9 at individualised imposed power outputs (PO) equating to 'light' $(40 \% \dot{\mathrm{VO}}$ 2peak) and

10 'moderate' $(60 \%$ VंO 2 peak $)$ intensity exercise. On a third occasion, participants were assigned to either the overall group or peripheral group and were required to self-regulate 12-min intermittent exercise according to either overall RPE or peripheral RPE reported during the corresponding imposed intensity trial.

Setting: Laboratory facilities at a university.

Participants: A preliminary population of able-bodied participants with no prior experience of wheelchair propulsion ( $\mathrm{n}=18)$.

Main Outcome Measures: Differences in oxygen uptake ( $\left.\dot{\mathrm{VO}}_{2}\right)$, heart rate, blood lactate concentration (BLa $\left.{ }^{-}\right)$and PO between the imposed and self-regulated exercise trials.

Results: No difference was found in physiological responses between the moderate intensity imposed and RPE-regulated trials in the peripheral group whereas a significant $(P<0.05)$

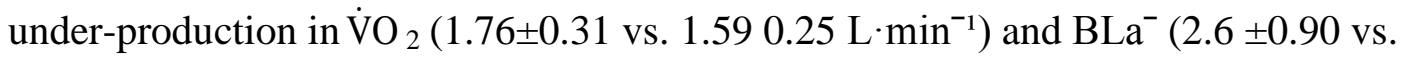
$\left.2.21 \pm 0.83 \mathrm{mmol} \cdot \mathrm{L}^{-1}\right)$ was seen in the overall group. In contrast a significant $(P<0.05)$ overproduction was seen in the peripheral group at a light exercise intensity whereas no difference between all variables during the light-intensity imposed and RPE-regulated trials in the overall group. 
26 Conclusion: Peripheral RPE enabled a more precise self-regulation during moderate-

27 intensity wheelchair exercise in novice users. In contrast overall RPE provided a more accurate stimulus when performing light-intensity propulsion.

29

30 Keywords: Exercise Prescription, Exercise intensity, Rehabilitation, Hand-rim propulsion

\section{Abbreviations}

$34 \mathrm{BLa}^{-}=$blood lactate concentration

$35 \mathrm{CI}_{\text {diff }}=$ confidence intervals of the difference

36 GXT = graded exercise test to exhaustion

$37 \quad$ HR $=$ heart rate

$38 \quad \mathrm{HR}_{\text {peak }}=$ heart rate peak

$39 \quad \mathrm{PF}=$ push frequency

$40 \quad \mathrm{VE}=$ minute ventilation

$41 \quad \mathrm{PO}=$ power Output

$42 \quad \mathrm{RPE}=$ rating of perceived exertion

$43 \quad \mathrm{RPE}_{\mathrm{C}}=$ central rating of perceived exertion

$44 \quad \mathrm{RPE}_{\mathrm{O}}=$ overall rating of perceived exertion

$45 \quad \mathrm{RPE}_{\mathrm{P}}=$ peripheral rating of perceived exertion

$46 \quad \dot{\mathrm{V}} \mathrm{O}_{2}=$ oxygen uptake

$47 \quad \dot{\mathrm{V}} \mathrm{O}_{2 \text { peak }}=$ peak oxygen uptake

$48 \quad$ ME $=$ Gross mechanical efficiency 
The majority of wheelchairs employed for daily ambulation and sports performance are hand-

rim propelled, which is reported to be one of the least efficient forms of

locomotion. ${ }^{1}$ However, wheelchair propulsion training and experience of manual wheelchair use show favourable effects on mechanical efficiency and physiological strain. ${ }^{2,3}$ Therefore, wheelchair practice is encouraged to enable participants to refine their propulsion technique, reduce feelings of physical strain and to ultimately encourage the confidence necessary to increase exercise adherence. ${ }^{4,5}$ Short term wheelchair skills training can improve factors determining quality of life, including self-esteem. ${ }^{5}$ Regular manual wheelchair exercise has been shown to improve cardiorespiratory fitness and endurance capacity, which can lead to an improved performance in activities of daily living and a reduction in chronic disease risk of over a life-span. ${ }^{6}$

Assessments of exercise intensity can be made during wheelchair propulsion training using standard open circuit spirometry procedures, in which oxygen uptake ( $\left.\dot{\mathrm{V}} \mathrm{O}_{2}\right)$ and power output (PO) are measured. However, the rehabilitation practitioner may not have access to the equipment required for these assessments on a day-to-day basis. Regulating exercise intensity solely on heart rate (HR) may also be unsuitable for some individuals with high thoracic (paraplegia) or cervical (tetraplegia) spinal cord injury due to an attenuated sympathetic innervation of the heart in response to exercise. ${ }^{7}$ It is therefore proposed that the rating of perceived exertion (RPE) may provide a convenient and inexpensive alternative to the aforementioned methods for regulating exercise intensity.,9

The ratings of perceived exertion have previously been employed for the prescription and self-regulation of exercise intensity across a range of exercise modalities, including treadmill 
exercise, cycling, arm-cranking, handcycling and wheelchair propulsion. ${ }^{10-14}$ Muller et al. ${ }^{12}$ reported small coefficients of variation (2.6 - 7.8\%) when self-regulating high-intensity wheelchair racing training according to a modified perceived exertion scale. Paulson et al. ${ }^{13}$ also reported that RPE can be used to self-regulate 20 min of moderate-intensity, manual wheelchair exercise in a group of highly trained athletes with tetraplegia. However, it is recognised that the strength of perceptual signals from the peripheral exercising limbs and joints (peripheral RPE) are greater than central signals from the cardiorespiratory system, such as HR and ventilation (central RPE), during sub-maximal wheelchair propulsion. ${ }^{3}$ Lenton et al. ${ }^{3}$ also observed that individuals inexperienced in wheelchair propulsion reported higher peripheral RPE compared to experienced users at the same relative exercise intensity. It is therefore important to consider the role of differentiated RPE in forming overall perceived exertion during manual wheelchair propulsion. However, to date no study has examined the ability of novice wheelchair users to self-regulate exercise or the potential role of peripheral RPE in improving the accuracy of self-regulated upper-body exercise.

The differentiated RPE model suggests that perceptual signals are related to specific anatomically regionalised processes during exercise. ${ }^{15}$ These differentiated RPE are then combined in a process termed 'perceptual signal integration' to create an overall undifferentiated RPE (overall RPE) ${ }^{16}$ It is recognised that the reliability of exercise intensity is improved with mode-specific familiarisation during low and moderate-intensity, selfregulated exercise guided by the overall RPE. ${ }^{12,14}$ However, the prescription and selfregulation of exercise may be enhanced in novice wheelchair users by using an RPE specific to the peripheral exertional signals experienced during hand-rim propulsion. 
The purpose of this study was to: 1) establish the differentiated RPE (peripheral and central) and undifferentiated (overall) RPE during sub-maximal wheelchair propulsion in novice individuals; and 2) examine whether utilising the differentiated RPE from the exercising limbs can improve the self-regulation of wheelchair exercise when compared to traditional overall RPE in the same novice group. It was hypothesised that RPE from the exercising muscle and joints would be greater than central RPE arising from the cardiorespiratory system during sub-maximal wheelchair propulsion. Furthermore, although the novice group would successfully self-regulate exercise based on overall RPE, employing an RPE specific to the exercising muscle mass and joints would improve the accuracy of the self-regulation process.

\section{Methods}

Participants

Eighteen recreationally active, able-bodied males volunteered to participate in the study. The participants’ characteristics are shown in Table 1. Procedures for the current investigation were approved by the University's Ethical Committee and performed in accordance with the Declaration of Helsinki. All participants provided written informed consent before testing commenced. Participants were physically active (>3h/wk) but not specifically upper-body trained and had no prior experience of wheelchair propulsion. Thus, the cohort employed was homogenous in both training status and wheelchair experience. This able-bodied participant group provided an experimental population in which to preliminarily examine the current hypotheses.

\section{Experimental design}


The study utilised a repeated measures design with participants visiting the laboratory on three separate occasions. During the first session, participants completed a sub-maximal incremental test and a graded exercise test to exhaustion to determine $\dot{\mathrm{V}} \mathrm{O}_{\text {2peak }}$. On a separate day, two 12-min intermittent exercise bouts consisting of three 4-min stages were completed at individualised imposed power outputs (PO) equating to 'light' ( $40 \%$ VंO $\left.{ }_{2 p e a k}\right)$ and 'moderate' (60\% $\dot{\mathrm{VO}}$ 2peak) intensity exercise (Fig. 1). On a third occasion, participants were assigned to either the overall group or peripheral group and were required to self-regulate 12min intermittent exercise according to either overall RPE or peripheral RPE reported during the corresponding imposed intensity trial (Fig. 1). Session 1 and session 2 were separated by $7 \mathrm{~d}$. The main experimental trials of sessions 2 and 3 were separated by at least $5 \mathrm{~d}$ but no longer than $7 \mathrm{~d}$.

\section{Instrumentation}

All testing was performed using a $15^{\circ}$ cambered sports wheelchair with $0.66 \mathrm{~m}$ diameter wheels and $0.61 \mathrm{~m}$ hand-rims (Quattro, RGK, Burntwood, Staffordshire, England). These are characteristics typical to sports wheelchair configuration used during the early stages of skill acquisition. ${ }^{17}$ The wheelchair was mounted on a wheelchair ergometer interfaced with a computer. The wheelchair ergometer consisted of a single roller (length, $1.14 \mathrm{~m}$; circumference, $0.48 \mathrm{~m}$ ). A flywheel sensor connected to the roller and interfaced to a computer calculated wheelchair velocity and displayed it visually on a computer monitor. Upon each visit participants performed two deceleration tests to allow PO to be calculated as described previously by Lenton et al. ${ }^{18}$ Briefly, for each deceleration trial the participant was asked to accelerate the roller to maximum velocity and to then stop pushing and sit stationary 
as if in a position to perform the next push. The velocity was recorded as the chair slowed to a standstill and the average deceleration calculated from the slope of this velocity-time data. PO was calculated from the torque applied to the wheels and their angular velocity. The torque applied is a function of one total internal torque of 1 ) the wheelchair ergometerwheelchair system, 2) the rotational moment of inertia of the rear wheels, 3) the one of the roller, and 4) its angular acceleration. ${ }^{18}$ Tyre pressure was set at 100 psi for each participant and standardised for each session. The Borg 6-20 scale was used to attain participants differentiated RPE throughout all trials. Participants were given standardised instructions detailing the use of the Borg 6-20 scale and the associated verbal anchors at the beginning of each session. ${ }^{8}$ To determine central RPE (RPE $E_{C}$, participants were asked to rate their perceived exertion for the heart, lungs and breathing., ${ }^{8,15}$ To determine peripheral RPE $\left(R P E_{P}\right)$, participants were asked to rate exertion only from the exercising muscle groups and joints. ${ }^{8,15}$ Overall RPE $\left(\mathrm{RPE}_{\mathrm{O}}\right)$ was then reported as the combination of $\mathrm{RPE}_{\mathrm{P}}$ and $\mathrm{RPE}_{\mathrm{C}}$. The RPE scale was visible to participants for the duration of each trial.

\section{Session 1}

On arrival at the laboratory, body mass was measured to the nearest $0.1 \mathrm{~kg}$, using wheelchair beam scales (Marsden MPWS-300, Henley-on-Thames, UK). The degree of elbow extension elicited by each participant when sitting upright with their hands positioned at top dead centre of the wheel was measured using a goniometer and standardised to an optimal angle of 100$120^{\circ}$, according to Woude et al. ${ }^{19}$ A standardised 5-min warm up of no greater than $1.5 \mathrm{~m} . \mathrm{s}^{-}$ ${ }^{1}$ was performed prior to all exercise sessions. Subsequently, participants performed an incremental exercise test consisting of five 4-min constant load exercise stages at ascending velocities, intended to elicit physiological responses covering a range from $40 \%$ to $80 \%$ VO 
2peak ${ }^{20}$ Initial speeds were $1.2 \pm 0.2 \mathrm{~m} . \mathrm{s}^{-1}$ with subsequent velocity increments of 0.2 or 0.3

m.s ${ }^{-1}$. HR was monitored continuously using radio telemetry (Polar PE 4000, Kempele, Finland). On-line respiratory gas analysis was carried out throughout each 4-min stage via a breath-by-breath system (Cortex metalyser 3B, Cortex, Leipzig, Germany). Before each test, gases were calibrated according to the manufacturer's recommendations using a 2-point calibration $(\mathrm{O} 2=17.0 \%, \mathrm{CO} 2=5.0 \%$ against room air $)$ and volumes with a 3 -L syringe at flow rates of 0.5-3.0 L.s ${ }^{-1}$. The average respiratory data from the last 1-min of each stage was used to provide information of oxygen uptake ( $\left.\dot{\mathrm{VO}}_{2}\right)$. A small capillary blood sample was obtained from the earlobe at the start of the test and during a 1-min break between stages to determine blood lactate concentration (BLa $\left.{ }^{-}\right)$using a YSI 1500 SPORT Lactate Analyser (YSI Inc, Yellow Springs, OH). Differentiated RPE were recorded in the last 15 s of each 4min stage while the participant was still exercising.

After a 15-min rest period, a graded exercise test to exhaustion was performed to determine $\dot{\mathrm{V}}{ }_{\text {2peak. }}$. The test involved increments of $0.1 \mathrm{~m} . \mathrm{s}^{-1}$ every minute from an initial velocity of 1.7 $\pm 0.6 \mathrm{~m} . \mathrm{s}^{-1}$ at a freely chosen push frequency until volitional exhaustion. HR and expired air were measured continuously throughout the test and the final differentiated RPE was recorded as previously described. Breath-by-breath data allowed the highest 30 s rolling average $\dot{\mathrm{V}} \mathrm{O}_{2}$ value recorded during the exercise test to be taken as the $\dot{\mathrm{V}} \mathrm{O}_{2 \text { peak }}$. For each participant a simple linear regression analysis was performed using the linear workload- $\dot{\mathrm{V}} \mathrm{O}_{2}$ relationship. The regression line created from the paired sub-maximal velocity and $\dot{\mathrm{V}}_{2}$ data was employed to interpolate individual velocities corresponding to a 'light' exercise intensity of $40 \%$ and a 'moderate' exercise intensity of $60 \% \dot{\mathrm{V}} \mathrm{O}_{2 \text { peak. }}$.

\section{Session 2: Imposed-intensity estimation trial}


A standardised 5-min warm up was performed prior to the imposed intensity trial and standardised for the RPE-regulated trial as previously described. The imposed intensity bouts were performed at individualised exercise intensities corresponding to $40 \%$ and $60 \% \dot{\mathrm{V}} \mathrm{O}_{\text {2peak }}$. Exercise intensities were presented in a counter-balanced order. Participants were informed of the velocity required and were asked to maintain it for 12 min of intermittent propulsion comprised of three 4-min stages separated by 3-min rest.. The different intensity bouts were separated by 20-min rest. Participants had full vision of their velocity on the computer monitor throughout the whole session. $\dot{\mathrm{V}} \mathrm{O}_{2}$, minute ventilation (VE), breathing frequency and HR were measured constantly during each bout and averaged over the final minute. Energy expenditure was obtained from $\dot{\mathrm{VO}}_{2}$ and associated respiratory exchange ratio (RER) by using the standard conversion table for the energy equivalent of oxygen. ${ }^{21}$ Gross mechanical efficiency was calculated according to principles of Woude et al. ${ }^{22}$ and defined as the ratio between external energy produced and internal energy expended. Push frequencies were retrospectively calculated from the velocity trace provided by the ergometer and averaged over the final 4-min bout of each trial. Differentiated RPE were recorded and $\mathrm{BLa}^{-}$determined in the last $15 \mathrm{~s}$ of each 4-min bout while the participant was still exercising. Collection of the RPE in the final stages of each 4-min bout of exercise is a valid means of assessing perceived exertion and is consistent with previous literature, ${ }^{14}$ on the basis that HR and $\dot{\mathrm{VO}}_{2}$ can be considered to have reached a steady-state after 3 minutes of continuous submaximal propulsion. The average recorded RPE during the 12-min pushing at light and moderate intensities were taken as the anchor for the intensity of the RPE-regulated bout. 
224 Participants were pair-matched for $\dot{\mathrm{V}} \mathrm{O}_{2 \text { peak }}$ and assigned to either the overall or peripheral group, where they were required to self-regulate exercise intensity using either $\mathrm{RPE}_{\mathrm{O}}$ or

$226 \mathrm{RPE}_{\mathrm{P}}$ respectively. Participants were informed of the average respective RPE recorded 227 during each imposed intensity trial and were instructed to reproduce a workload equating to these RPE for each 4-min stage in the 12-min bouts. Participants were blinded to their velocity and all physiological measurements but were informed of time elapsed. Breathing frequency, $\dot{\mathrm{VO}}{ }_{2}, \mathrm{VE}, \mathrm{HR}, \mathrm{BLa}^{-}$, push frequency and gross mechanical efficiency were measured in accordance with the imposed intensity trials. PO was also recorded and averaged over each minute. Participants were reminded of their target RPE prior to each 4-min stage.

Statistical Analysis

All data was analysed using the statistical package IBM SPSS version 19 for windows (SPSS inc, Chicago, IL). Using previously published experimental data by Kang et al ${ }^{23}$, statistical package GPower 3.1.5 indicated a minimum sample size of 16 participants (8 participants per group) was required to determine similar differences in PO between trials, with an effect size of $1.2,90 \%$ power and an $\alpha$ of $5 \%$. Subsequently 18 participants were recruited. Normal distribution of the outcome variables was confirmed by Shapiro-Wilk test $\left(W_{(10)}=0.83-\right.$ $0.98, P=0.07-0.94)$. All descriptives are presented as mean \pm standard deviation (SD) with the exception of ordinal RPE data which are reported as median and quartile range.

Differences in $\dot{\mathrm{V}}{ }_{\text {2peak }}$ and age between groups were examined using Student's dependent ttests, as were paired values for $\dot{\mathrm{V}} \mathrm{O}_{2}, \% \dot{\mathrm{V}} \mathrm{O}_{2 \text { peak, }} \mathrm{PO}$, velocity, VE, breathing frequency, HR, $\% \mathrm{HR}_{\text {peak, }} \mathrm{BLa}^{-}$, gross mechanical efficiency and push frequency averaged during the 12 -min exercise bouts between the imposed and RPE regulated trials. 95\% confidence intervals of the differences $\left(95 \% \mathrm{CI}_{\text {diff }}\right.$ ) are also provided. A 3-way (trial-by-intensity-by-group) mixed 
measures ANOVA was performed on all the variables above. In addition a 3-way (trial-bygroup-by-time) mixed measures ANOVA was performed on the PO data from both the light and moderate intensity bouts to examine the responses across time. Non-parametric Friedman tests and Wilcoxon signed-rank tests were used to analyse differences in ordinal differentiated RPE data at both sub-maximal imposed intensities. Significance was set a priori at $P \leq 0.05$. A Bonferroni adjustment was performed on the alpha value when performing multiple comparisons. Effect sizes (ES) are presented whereby 0.2 refers to a small effect, 0.5 a moderate effect and 0.8 a large effect. ${ }^{24}$

\section{Results}

Participants' peak physiological responses are shown in Table 1. Table 2 shows the differentiated RPE responses for the sub-maximal imposed intensity trials. Non-parametric difference tests found $\mathrm{RPE}_{\mathrm{P}}$ and $\mathrm{RPE}_{\mathrm{O}}$ to be greater than $\mathrm{RPE}_{\mathrm{C}}$ at both intensities. In turn, $\mathrm{RPE}_{\mathrm{P}}$ was greater than $\mathrm{RPE}_{\mathrm{O}}$ during moderate-intensity propulsion only.

Age, $\dot{\mathrm{V} O}{ }_{2 \text { peak }}$ and body weight were consistent between groups. Comparisons between the imposed and RPE-regulated trials were made using paired sample t-tests and ES as shown in Tables 3 and 4. Negative ES and significantly lower $\dot{\mathrm{V}} \mathrm{O}_{2}, \% \dot{\mathrm{V}} \mathrm{O}_{2 \text { peak }}$ and $\mathrm{BLa}^{-}$were present for the overall group during moderate intensity exercise when comparing the imposed and RPE-regulated trials. No significant differences were present between trials for the peripheral group at the same exercise intensity, with smaller $\mathrm{ES}$ and $95 \% \mathrm{CI}_{\text {diff }}$ compared to the overall group. In contrast, the overall group displayed smaller ES and $95 \% \mathrm{CI}_{\text {diff }}$ and no significant differences between the light-intensity imposed and RPE-regulated trials. A significant over- 
273 production and larger ES were present for $\dot{\mathrm{V}} \mathrm{O}_{2}, \% \dot{\mathrm{V}}{ }_{2 p e a k}, \mathrm{HR}, \mathrm{PO}$ and $\mathrm{BF}$ in the peripheral 274 group at the same intensity.

276 For the 3-way trial-by-intensity-by group ANOVA, significant main effects for intensity $(P<0.001)$ for $\dot{\mathrm{V} O}{ }_{2}, \% \dot{\mathrm{V}}{ }_{2 p e a k}, \mathrm{BLa}^{-}, \mathrm{HR}, \% \mathrm{HR}_{\text {peak }}$, push frequency, breath frequency, VE and PO indicated the manipulation of exercise intensity was successful, with all values greater in the moderate intensity trials than the light intensity trials. No difference in gross mechanical efficiency was found between the imposed and RPE-regulated bouts for either group at both intensities. Average efficiency for all participants was $6.3 \pm 0.8 \%$. The 3-way time-by-trial-by group analysis confirmed PO was consistent across time for both the light (Fig. 1) and moderate (Fig. 2) intensity RPE-regulated trials.

\section{Discussion}

The present study examined the hypothesis that the differentiated RPE can provide a mode specific stimulus to improve the precision of self-regulated wheelchair exercise in novice users. In accordance with Lenton et al., ${ }^{3}$ RPE from the exercising muscle mass and joints was the dominant perceptual signal during sub-maximal wheelchair propulsion. Utilising these dominant peripheral RPE improved the precision of moderate intensity, self-regulated exercise (RPE = 13 'somewhat hard') in this novice group, with an under-production in exercise intensity seen when incorporating both peripheral and central signals of exertion to form undifferentiated RPE. However the employment of peripheral RPE to self-regulate light-intensity exercise (RPE = 9-11 'very light - fairly light) resulted in a significant overproduction in exercise intensity which was not present when using undifferentiated RPE. 
The perceptual dominance of peripheral RPE during manual hand-rim propulsion can be attributed to a combination of physiological and biomechanical factors. Oxygen availability is restricted during upper-body exercise as a result of an impaired perfusion capacity of the upper-limb. ${ }^{25}$ Oxidative enzyme activity is also limited in previously untrained upper-limb muscles. ${ }^{26}$ This impaired aerobic capability results in elevated lactate production and subsequent acidosis of exercising tissue during upper-limb versus lower-limb exercise of a comparable intensity, ${ }^{27}$ thereby elevating peripheral feelings of exertion. ${ }^{28}$ Specific to wheelchair users, manual hand-rim propulsion is associated with neurologic and muscular pain in the wrist and shoulder joints due to high mechanical loads. ${ }^{1,29}$ Novice users also exhibit a lower mechanical efficiency compared to experienced users as a result of inferior co-ordination, with technique parameters such as timing and stroke angle improving task muscular strain in novice users. ${ }^{2}$

\section{Differentiated RPE and self-regulated exercise}

Perceptually-regulated exercise training has been employed to achieve gains in cardiovascular health and fitness. ${ }^{9}$ In this method, the RPE are employed in 'production' mode, allowing individuals to self-regulate the intensity of exercise based on subjective exertional responses. ${ }^{9,11,13,14}$ The target RPE can be 'estimated' during prior exercise tasks of

321 a known intensity ${ }^{11,13}$ or clamped at a fixed RPE for a whole cohort. ${ }^{9}$ To date, overall RPE 322 has traditionally been employed as the stimulus for self-regulated exercise. However, 
peripheral RPE is the dominant contributing factor to overall RPE during wheelchair propulsion $^{3}$ and other modes of upper-extremity exercise. ${ }^{15,30}$ As shown in Table 4, the present findings suggest a mode specific differentiated RPE, based on the aforementioned dominant peripheral signals, can improve the precision of moderate-intensity, self-regulated wheelchair exercise in individuals unaccustomed to the demands of hand-rim propulsion. The significantly lower relative oxygen uptake, $\mathrm{VE}$ and $\mathrm{BLa}^{-}$when self-regulating moderate intensity exercise based on overall RPE indicate lower levels of physiological strain compared to the target 'imposed' intensity trial. In a practical setting, an under-production in exercise intensity, as seen with undifferentiated RPE, may result in an insufficient training load being performed. Subsequently, targeted outcomes of training, whether functional or performance based, may not be attained. The current findings contrast with the successful self-regulation of moderate intensity wheelchair exercise reported in a group of experienced users employing undifferentiated RPE. ${ }^{13}$ However, experienced users have a greater familiarisation with the dominance in peripheral RPE during wheelchair propulsion. Therefore a focus on these peripheral signals during self-regulated exercise may have facilitated the successful findings despite the employment of overall RPE.

An unexpected finding of this study was the over-production in light-intensity exercise, a method frequently applied for wheelchair skills training, ${ }^{4}$ when employing peripheral RPE (Table 3). Oxygen uptake, HR, BLa-, PO and BF were all significantly higher than the corresponding imposed intensity trial. The aforementioned factors regulating peripheral exertion, including mechanical work and muscle lactate production, were significantly lower for the light-intensity exercise than the moderate-intensity exercise. This over-production may therefore represent the insensitivity of novice users to small alterations in these peripheral signals and the elevation in workload required to achieve perceptible changes 
whilst producing light-exercise intensities. Since an over-production in prescribed exercise intensity may have deleterious consequences on health, including over-use injury or cardiovascular strain, and may induce premature fatigue during exercise training, overall RPE should be considered a more applicable tool for self-regulating low-intensity training prior to further familiarisation in wheelchair propulsion. The effect of familiarisation on the accuracy of low-intensity self-regulated wheelchair exercise utilising mode specific differentiated RPE requires investigation.

\section{Study limitations}

The application of a novice, able-bodied population in this study allowed for a cohort homogenous in training status and wheelchair experience in which to preliminarily examine the current hypotheses. Literature has frequently reported that responses in able-bodied nonwheelchair user groups comply with the overall trends in physiology as shown by wheelchair users. $^{2,3,22,31}$ However the sensorimotor and cardiovascular adaptations associated with cervical level spinal cord injury require the verification of these findings in novice tetraplegic groups. Longitudinal work is also required to assess the efficacy of perceptually-regulated wheelchair based training using differentiated RPE. In the current protocol, the preliminary testing and the imposed intensity exercise trial preceded the RPE-regulated trials. The ability of the participants to self-regulate exercise intensity may therefore have been facilitated by the performance of these previous sessions and the experience gained using RPE scales. This factor should be taken into consideration when considering the application of these findings. Further work is required to investigate the role of familiarisation training with rating RPE on the accuracy of self-regulated wheelchair exercise. The current work also only investigates 
constant load wheelchair propulsion and future work should extend these findings to activities of daily living or more practical rehabilitation based sessions.

\section{Conclusion}

In conclusion, peripheral RPE provided the dominant perceptual signal during sub-maximal wheelchair exercise. When self-regulating exercise based on perceptual exertional signals, peripheral RPE enabled a more precise self-regulation of moderate-intensity wheelchair exercise in a novice user group than overall RPE. In contrast, overall RPE provided a more accurate self-regulation tool during light-intensity exercise and should be employed prior to familiarisation with differentiated RPE during light-intensity wheelchair propulsion training.

\section{References}

1. Woude van der LHV, Veeger HE, Dallmeijer AJ, Janssen TW, Rozendaal LA. Biomechanics and physiology in active manual wheelchair propulsion. Med Eng Phys 2001; 23:713-733

2. Dallmeijer A, Zentgraaff I, Zijp N, Van der Woude LHV. Submaximal physical strain and peak performance in handcycling versus handrim wheelchair propulsion. Spinal Cord 2004; 42:91-98

3. Lenton JP, Fowler NE, van Der Woude L, Goosey-Tolfrey VL. Wheelchair propulsion: effects of experience and push strategy on efficiency and perceived exertion. Appl Physiol Nutr Metab 2008; 33:870-879

4. De Groot S, de Bruin M, Noomen SP, Van der Woude, L.H. Mechanical efficiency and propulsion technique after 7 weeks of low-intensity wheelchair training. Clin Biomech 2008; 23:434-441 
5. MacPhee AH, Kirby RL, Coolen AL, Smith C, MacLeod DA, Dupuis DJ. Wheelchair skills training program: a randomized clinical trial of wheelchair users undergoing initial rehabilitation. Arch Phys Med Rehabil 2004; 85:41-50

6. Bougenot M-P, Tordi N, Betik AC, Martin X, Le Foll D, Parratte B, Lonsdorfer J and Rouillon JD. Effects of wheelchair ergometer training programme on spinal cordinjured persons. Spinal Cord 2003; 41:451-456

7. Valent L, Dallmeijer A, Houdijk H, Slootman J, Janssen T, Hollander A. The individual relationship between heart rate and oxygen uptake in people with a tetraplegia during exercise. Spinal Cord 2007; 45:104-111

8. Borg G. Borg's perceived exertion and pain scales. Human Kinetics Publishers, Champaign, Il 1998.

9. Parfitt G, Evans H, Eston R Perceptually-regulated training at RPE13 is pleasant and improves physical health. Med Sci Sports Exerc 2012; 44:1613-1618

10. Eston R. Use of ratings of perceived exertion. Int J Sports Phys Perform 2012; 7:175182

11. Goosey-Tolfrey V, Lenton J, Goddard J, Oldfield V, Tolfrey K, Eston R. Regulating intensity using perceived exertion in spinal cord-injured participants. Med Sci Sports Exerc 2010; 42:608-613

12. Müller G, Odermatt P, Perret C A new test to improve the training quality of wheelchair racing athletes. Spinal Cord 2004; 42:585-590

13. Paulson TAW, Bishop NC, Leicht CA, Goosey-Tolfrey VL Perceived exertion as a tool to self-regulate exercise in individuals with tetraplegia. Eur J Appl Physiol 2013; $113: 201-209$

14. Eston R, Williams J. Reliability of ratings of perceived effort regulation of exercise intensity. Br J Sports Med 1988; 22:153-155 
15. Pandolf KB, Billings DS, Drolet LL, Pimental NA, Sawka MN. Differentiated ratings of perceived exertion and various physiological responses during prolonged upper and lower body exercise. Eur J Appl Physiol Occup Physiol 1984; 53:5-11

16. Robertson RJ and Noble BJ. Perception of physical exertion: methods, mediators, and applications. Exerc Sport Sci Rev 1997; 25:407-452

17. Goosey-Tolfrey VL, West M, Lenton JL, Tolfrey, K. Influence of varied tempo music on wheelchair mechanical efficiency following 3-wk practice. Int J Sports Med 2011; 32:126-131.

18. Lenton JP, Fowler NE, van Der Woude L, Goosey-Tolfrey VL. Efficiency of wheelchair propulsion and effects of strategy. Int. J. Sports. Med 2007; 28:1-6

19. Woude van der LHV, De Groot G, Hollander AP, Ingen Schenau GJ van, Rozendal RH. Wheelchair ergonomics and physiological testing of prototypes. Ergonomics 1986; 29:1561-1573

20. Goosey-Tolfrey V. The disabled Athlete In: Winter E, Jones A, Davison, R, Bromley P, Mercer T, (eds) BASES sport and exercise physiology testing guidelines, Vol. 1: sport testing. Routledge, Oxford; 2008: p359-367

21. Peronnet F, Massicotte D Table of non-protein respiratory quotient: An update. Canadian J Sport Sci 1991; 16:23-29

22. Woude van der LHV, Veeger HEJ, Rozendal R, Sargeant A. Optimum cycle frequencies in hand-rim wheelchair propulsion. Eur J Appl Physiol Occup Physiol 1989; 58:625-632

23. Kang J, Chaloupka E, Biren G, Mastrangelo M, Hoffman J. Regulating intensity using perceived exertion: effect of exercise duration. Eur J Appl Physiol 2009; 105:445-451.

24. Cohen J. A Power Primer. Psych Bulletin 1992; 112:155-159 
25. Calbet J, Holmberg H, Rosdahl H, van Hall G, Jensen-Urstad M, Saltin B. Why do arms extract less oxygen than legs during exercise? Am J Physiol Regul Integr Comp Physiol 2005; 289:R1448-R1458

26. Killerich K, Girk J, Damsgaard R, Wojtaszewski J, Pilegaard H. Regulation of PDH in human arm and leg muscles at rest and during intense exercise. Am J Physiol Endocrniol Metab 2008; 294:E36-E42

27. Helge JW. Arm and leg substrate utilisation and muscle adaptation after prolonged low-intensity training. Acta Physio 2010; 199:519-528

28. Hampson DB, Gibson ASC, Lambert MI, Noakes TD. The influence of sensory cues on the perception of exertion during exercise and central regulation of exercise performance. Sports Med 2001; 31:935-952

29. Boninger ML, Souza AL, Cooper RA, Fitzgerald SG, Koontz AM, Fay BT. Propulsion patterns and pushrim biomechanics in manual wheelchair propulsion. Arch Phys Med Rehabil 2002; 83:718-723

30. Al-Rahamneh H, Faulkner J, Byrne C, Eston R. Relationship between perceived exertion and physiologic markers during arm exercise with able-bodied participants and participants with poliomyelitis. Arch Phys Med Rehabil 2012 91:273-277

31. Brown DD, Knowlton RG, Hamill J, Schneider TL, Hetzler RK. Physiological and biomechanical differences between wheelchair-dependent able-bodied subjects during wheelchair ergometry. Eur J Appl Physiol 1990; 60:179-182

\section{Suppliers List}

RGK Wheelchairs Ltd, Units 8a/b/c,, Ring Road, Zone 2, Burntwood Business Park, Burntwood, Staffordshire, WS7 3JQ 
469 Marsden, Anvil House, Tuns Lane, Henley-on-Thames, Oxfordshire, RG9 1SA

470 Polar Polar Electro (UK) Ltd, Polar House, Unit L, Heathcote Way, Heathcote Industrial

471 Estate, Warwick CV34 6TE, England

472 Cortex Biophysik GmbH, Walter-Köhn, Str. 2d, 04356, Leipzig, Germany

473 YSI Incorporated, 1700/1725 Brannum Lane, Yellow Springs, OH 45387 USA

$475 \quad$ Figure Legends

476 Fig 1 Schematic representation of experimental protocol for the Imposed-intensity (session 2)

477 and RPE-regulated (session3) trials

478 Fig 2 Minute by minute power output data for the $40 \% \dot{\mathrm{V}}{ }_{2 p e a k}$ trials for the peripheral and 479 overall groups

480 Fig 3 Minute by minute power output data for the $60 \% \dot{\mathrm{V}} \mathrm{O}_{2 \text { peak }}$ trials for the peripheral and 481 overall groups 
Table 1 Participants' characteristics

\begin{tabular}{|c|c|c|c|}
\hline & $\begin{array}{c}\text { Whole cohort } \\
\qquad(\mathrm{n}=18)\end{array}$ & $\begin{array}{c}\text { Peripheral } \\
\quad(n=9)\end{array}$ & $\begin{array}{l}\text { Overall } \\
(n=9)\end{array}$ \\
\hline Age (yr) & $23 \pm 2$ & $23 \pm 2$ & $22 \pm 2$ \\
\hline Body Mass (kg) & $77.7 \pm 9.6$ & $77.2 \pm 6.3$ & $78.1 \pm 12.0$ \\
\hline Height (cm) & $181 \pm 7$ & $182 \pm 7$ & $180 \pm 8$ \\
\hline$\dot{\mathrm{V}} \mathrm{O}_{2 p e a k}\left(\mathbf{L} \cdot \mathbf{m i n}^{-1}\right)$ & $2.91 \pm 0.32$ & $2.81 \pm 0.17$ & $2.93 \pm 0.39$ \\
\hline$H_{\text {peak }}\left(b \cdot \min ^{-1}\right)$ & $170 \pm 11$ & $172 \pm 7$ & $171 \pm 15$ \\
\hline
\end{tabular}

$\mathrm{PER}=$ Peripheral group; OVR = Overall group; $\dot{\mathrm{V}} \mathrm{2peak}_{\text {}}=$ peak oxygen uptake; $\mathrm{HR}_{\text {peak }}=$ Heart rate peak. Data are (mean \pm SD) 
Table 2 Differentiated RPE responses during imposed intensity submaximal exercise $(n=18)$

\begin{tabular}{lccc}
\hline & $\mathrm{RPE}_{\mathrm{P}}$ & $\mathrm{RPE}_{\mathrm{C}}$ & $\mathrm{RPE}_{\mathrm{O}}$ \\
\hline $\mathbf{4 0 \%} \dot{\mathrm{V} O}{ }_{2 \text { peak }}$ & $10(9,11) \ddagger$ & $9(8,10)$ & $10(8,12) \ddagger$ \\
$\mathbf{6 0 \%} \dot{\mathrm{V} O}{ }_{2 \text { peak }}$ & $13(13,14) \dagger$ & $12(11,13)$ & $13(12,13) \ddagger$ \\
\hline
\end{tabular}

$R P E_{P}=$ peripheral rating of perceived exertion; $R P E_{C}=$ central rating of perceived exertion; $\mathrm{RPE}_{\mathrm{O}}=$ overall rating of perceived exertion; $\dot{\mathrm{V}}{ }_{2 \text { peak }}=$ peak oxygen uptake; Data are median (quartiles). $P \leq 0.05$.

$\dagger=$ significantly different from both $\mathrm{RPE}_{\mathrm{C}}$ and $\mathrm{RPE}_{\mathrm{O}} \ddagger=$ significantly different from $\mathrm{RPE}_{\mathrm{C}}$ 
Table 3 Physiological responses during 12 min imposed intensity and RPE-regulated wheelchair propulsion at $40 \% \dot{\mathrm{V} O}$ 2peak

\begin{tabular}{|c|c|c|c|c|c|}
\hline & $\begin{array}{l}\text { Imposed } \\
\text { intensity }\end{array}$ & $\begin{array}{c}\text { RPE } \\
\text { regulated }\end{array}$ & $95 \% C I_{\text {diff }}$ & $\begin{array}{l}\text { P-value } \\
\text { (T-Test) }\end{array}$ & $\begin{array}{c}\text { Effect } \\
\text { Size }\end{array}$ \\
\hline \multicolumn{6}{|l|}{ Peripheral } \\
\hline $\mathbf{R P E}_{\mathbf{P}}$ & $11(10,12)$ & $11(10,12)$ & - & - & - \\
\hline$\dot{\mathrm{V} O}{ }_{2}\left(\mathbf{L} \cdot \mathbf{m i n}^{-1}\right)$ & $1.14 \pm 0.15$ & $1.29 \pm 0.13$ & -0.27 to -0.03 & $0.02 \dagger$ & 1.15 \\
\hline \% VंO 2peak & $39 \pm 4$ & $45 \pm 4$ & -10 to -1 & $0.02 \dagger$ & 1.45 \\
\hline HR (b. min $^{-1}$ ) & $91 \pm 12$ & $98 \pm 5$ & -15 to 1 & $0.05 \dagger$ & 0.83 \\
\hline$\% \mathrm{HR}_{\text {peak }}$ & $54 \pm 8$ & $58 \pm 4$ & -8 to 0 & $0.05 \dagger$ & 0.65 \\
\hline $\mathrm{BLa}^{-}\left(\mathrm{mmol} \cdot \mathbf{L}^{-1}\right)$ & $1.39 \pm 0.42$ & $1.88 \pm 0.62$ & -0.75 to 0.18 & 0.19 & 0.54 \\
\hline Power Output (W) & $26 \pm 3$ & $32 \pm 4$ & -9 to -2 & $0.01 \dagger$ & 1.74 \\
\hline Br Freq $\left(1 \cdot \mathbf{m i n}^{-1}\right)$ & $22 \pm 5$ & $24 \pm 5$ & -5 to 0 & $0.04 \dagger$ & 0.40 \\
\hline $\mathrm{VE}\left(\mathrm{L} \cdot \mathrm{min}^{-1}\right)$ & $25.3 \pm 2.1$ & $27.8 \pm 3.6$ & -5.6 to 0.4 & 0.08 & 0.88 \\
\hline ME (\%) & $6.7 \pm 0.6$ & $6.9 \pm 0.7$ & -0.7 to 0.4 & 0.44 & 0.36 \\
\hline$P F\left(p \cdot \min ^{-1}\right)$ & $26 \pm 9$ & $27 \pm 10$ & -4 to 5 & 0.76 & 0.16 \\
\hline \multicolumn{6}{|l|}{ Overall } \\
\hline $\mathrm{RPE}_{\mathbf{O}}$ & $9(8,11)$ & $9(8,11)$ & - & - & - \\
\hline$\dot{\mathrm{V} O}{ }_{2}\left(\mathbf{L} \cdot \mathbf{m i n}^{-1}\right)$ & $1.19 \pm 0.19$ & $1.20 \pm 0.15$ & -0.18 to 0.15 & 0.40 & 0.10 \\
\hline \% VंO 2peak & $40 \pm 3$ & $42 \pm 5$ & -5 to 1 & 0.20 & 0.33 \\
\hline HR (b. $\left.\min ^{-1}\right)$ & $91 \pm 12$ & $95 \pm 14$ & -10 to 1 & 0.12 & 0.18 \\
\hline$\% \mathbf{H R}_{\text {peak }}$ & $53 \pm 5$ & $56 \pm 6$ & -5 to 1 & 0.11 & 0.37 \\
\hline $\mathrm{BLa}^{-}\left(\mathrm{mmol} \cdot \mathbf{L}^{-1}\right)$ & $1.27 \pm 0.63$ & $1.40 \pm 0.72$ & -0.35 to 0.10 & 0.24 & 0.19 \\
\hline Power Output (W) & $26 \pm 3$ & $28 \pm 4$ & -5 to 1 & 0.10 & 0.38 \\
\hline $\operatorname{Br}$ Freq $\left(1 \cdot \min ^{-1}\right)$ & $23 \pm 2$ & $24 \pm 2$ & -1 to 3 & 0.20 & 0.39 \\
\hline $\operatorname{VE}\left(\mathbf{L} \cdot \min ^{-1}\right)$ & $26.2 \pm 3.7$ & $27.2 \pm 5.8$ & -4.8 to 1.8 & 0.10 & 0.21 \\
\hline ME (\%) & $6.2 \pm 0.4$ & $6.1 \pm 0.6$ & -0.5 to 0.4 & 0.79 & -0.20 \\
\hline$P F\left(p \cdot \min ^{-1}\right)$ & $23 \pm 12$ & $25 \pm 13$ & -6 to 2 & 0.27 & 0.11 \\
\hline
\end{tabular}

$\mathrm{CI}_{\text {diff }}$ = confidence intervals of the difference; $\mathrm{RPE}_{\mathrm{P}}=$ peripheral rating of perceived exertion; $\mathrm{RPE}_{\mathrm{O}}=$ overall rating of perceived exertion; RPE = rating of perceived exertion; $\dot{\mathrm{VO}}_{2}=$ oxygen uptake; $\dot{\mathrm{V}} \mathrm{O}_{2 \text { peak }}=$ peak oxygen uptake; $\mathrm{HR}=$ heart rate; $\mathrm{HR}_{\text {peak }}=$ heart rate peak; $\mathrm{BLa}^{-}=$blood lactate concentration; $\mathrm{Br}$ Freq = breath frequency; $\mathrm{VE}=$ minute ventilation; $\mathrm{PF}$ = push frequency; $\mathrm{ME}=$ mechanical efficiency.

$\dagger=$ significant difference between imposed and RPE-regulated trials $(\mathrm{P} \leq 0.05)$ 
Table 4 Physiological responses during 12 min imposed intensity and RPE-regulated wheelchair propulsion at $60 \% \dot{\mathrm{V}} \mathrm{Z}_{2 \text { peak }}$

\begin{tabular}{|c|c|c|c|c|c|}
\hline & $\begin{array}{l}\text { Imposed } \\
\text { intensity }\end{array}$ & $\begin{array}{c}\mathrm{RPE} \\
\text { regulated }\end{array}$ & $95 \% \mathrm{CI}_{\text {diff }}$ & $\begin{array}{l}\text { P-value } \\
\text { (T-Test) }\end{array}$ & $\begin{array}{c}\text { Effect } \\
\text { size }\end{array}$ \\
\hline \multicolumn{6}{|l|}{ Peripheral } \\
\hline $\mathbf{R P E}_{\mathbf{P}}$ & $13(13,15)$ & $13(13,15)$ & - & - & - \\
\hline$\dot{\mathrm{V}}{ }_{2}\left(\mathbf{L} \cdot \mathbf{m i n}^{-1}\right)$ & $1.64 \pm 0.19$ & $1.78 \pm 0.26$ & -0.34 to 0.01 & 0.13 & 0.63 \\
\hline$\% \dot{\mathrm{V} O}{ }_{2 \text { peak }}$ & $58 \pm 3$ & $62 \pm 7$ & -7 to 0 & 0.07 & 0.67 \\
\hline HR $\left(b \cdot \min ^{-1}\right)$ & $107 \pm 11$ & $111 \pm 9$ & -8 to 2 & 0.20 & 0.31 \\
\hline$\%$ HR $_{\text {peak }}$ & $66 \pm 9$ & $66 \pm 7$ & -5 to 5 & 0.98 & 0.04 \\
\hline $\mathrm{BLa}^{-}\left(\mathrm{mmol} \cdot \mathbf{L}^{-1}\right)$ & $2.56 \pm 0.56$ & $2.62 \pm 0.73$ & -0.65 to 0.53 & 0.82 & 0.09 \\
\hline Power Output (W) & $37 \pm 2$ & $39 \pm 4$ & -4 to -0 & 0.08 & 0.55 \\
\hline Br Freq $\left(1 \cdot \min ^{-1}\right)$ & $29 \pm 5$ & $30 \pm 4$ & 3 to 4 & 0.70 & 0.22 \\
\hline $\operatorname{VE}\left(L \cdot \min ^{-1}\right)$ & $37.1 \pm 13.5$ & $39.5 \pm 8.5$ & -9.8 to 4.0 & 0.36 & 0.26 \\
\hline ME (\%) & $6.1 \pm 0.7$ & $6.1 \pm 0.6$ & -0.1 to 0.3 & 0.35 & 0.01 \\
\hline$P F\left(p \cdot \min ^{-1}\right)$ & $31 \pm 9$ & $32 \pm 13$ & -6 to 4 & 0.67 & 0.09 \\
\hline \multicolumn{6}{|l|}{ Overall } \\
\hline $\mathbf{R P E}_{\mathbf{O}}$ & $13(12,14)$ & $13(12,14)$ & - & - & - \\
\hline$\dot{\mathrm{V}} \mathrm{O}_{2}\left(\mathbf{L} \cdot \mathbf{m i n}^{-1}\right)$ & $1.76 \pm 0.31$ & $1.59 \pm 0.25$ & 0.05 to 0.33 & $0.04 \dagger$ & -0.74 \\
\hline$\% \dot{\mathrm{V} O}{ }_{2 \text { peak }}$ & $60 \pm 3$ & $53 \pm 6$ & 3 to 10 & $0.01 \dagger$ & -1.37 \\
\hline HR $\left(b \cdot \min ^{-1}\right)$ & $113 \pm 19$ & $108 \pm 17$ & -3 to 13 & 0.18 & -0.31 \\
\hline$\% \mathbf{H R}_{\text {peak }}$ & $66 \pm 8$ & $63 \pm 8$ & -2 to 7 & 0.18 & -0.36 \\
\hline $\mathrm{BLa}^{-}\left(\mathrm{mmol} \cdot \mathbf{L}^{-1}\right)$ & $2.68 \pm 0.90$ & $2.21 \pm 0.83$ & 0.13 to 0.81 & $0.01 \dagger$ & -0.45 \\
\hline Power Output (W) & $37 \pm 3$ & $35 \pm 2$ & -1 to 5 & 0.11 & -0.68 \\
\hline Br Freq $\left(1 \cdot \mathrm{min}^{-1}\right)$ & $28 \pm 3$ & $28 \pm 5$ & -4 to 3 & 0.85 & 0.00 \\
\hline $\operatorname{VE}\left(\mathbf{L} \cdot \mathbf{m i n}^{-1}\right)$ & $39.0 \pm 9.0$ & $34.4 \pm 6.5$ & -0.8 to 10.0 & 0.08 & -0.59 \\
\hline ME (\%) & $5.9 \pm 0.7$ & $6.1 \pm 0.8$ & -0.9 to 0.5 & 0.54 & 0.27 \\
\hline PF $\left(p \cdot \min ^{-1}\right)$ & $31 \pm 10$ & $32 \pm 13$ & -5 to 3 & 0.51 & 0.09 \\
\hline
\end{tabular}

$\mathrm{CI}_{\text {diff }}=$ confidence intervals of the difference; $\mathrm{RPE}_{\mathrm{P}}=$ peripheral rating of perceived exertion; $\mathrm{RPE}_{\mathrm{O}}=$ overall rating of perceived exertion; RPE = rating of perceived exertion; $\dot{\mathrm{VO}}_{2}=$ oxygen uptake; $\dot{\mathrm{V}} \mathrm{O}_{2 \text { peak }}=$ peak oxygen uptake; $\mathrm{HR}=$ heart rate; $\mathrm{HR}_{\text {peak }}=$ heart rate peak; $\mathrm{BLa}^{-}=$blood lactate concentration; $\mathrm{Br}$ Freq $=$ breath frequency; $\mathrm{VE}=$ minute ventilation; $\mathrm{PF}$ = push frequency; $\mathrm{ME}=$ mechanical efficiency.

$\dagger=$ significant difference between imposed and RPE-regulated trials $(\mathrm{P} \leq 0.05)$ 
